\title{
AS REDES SOCIAIS DE APOIO NA TRANSIÇÃO PARA A PARENTALIDADE
}

\section{SOCIAL SUPPORT NETWORKS IN THE TRANSITION TO PARENTHOOD}

\author{
Ana Rosa Pinto \\ Centro Hospitalar Cova da Beira, E.P.E., Quinta do Alvito, 6200-251 Covilhã, Portugal. Email: \\ anarosa.pinto@gmail.com
}

Alcides A. Monteiro

Departamento de Sociologia, Faculdade de Ciências Sociais e Humanas, Universidade da Beira Interior \& Centro

de Investigação e Estudos de Sociologia, Instituto Universitário de Lisboa, CIES-IUL. Universidade da Beir

Interior, Faculdade de Ciências Sociais e Humanas, Estrada do Sineiro, 6200-209 Covilhã, Portugal. Email:

alcidesmonteiro@ubi.pt

Resumo: Tomando como referência o cenário de diminuição dos nascimentos verificado em Portugal, vários autores têm assinalado a importância das redes sociais de apoio como incentivo à natalidade e fonte de auxílio na transição para a parentalidade. Neste estudo analisa-se a relação entre a identificação e utilização de redes sociais de apoio pelos pais e o papel destas redes na transição para a parentalidade. Conclui-se que a existência de redes sociais de apoio não determina nem condiciona a decisão das famílias em ter filhos, mas o apoio que recebem das mesmas, designadamente da rede informal, é relevante para facilitar o processo de transição.

Palavras-chave: natalidade, parentalidade, transição, redes sociais.

Abstract: In a context characterized by declining birth rates in Portugal, several authors have pointed out the importance of social support networks to encourage child birth and as a support system in the transition to parenthood. This study aims to analyse the relation between the identification and use of social support networks by parents and the role of these networks in the transition to parenthood. The main conclusion is that the existence of social support networks does not impact on the decision to have children. However, the support families receive from these networks, namely from the informal network, facilitates the transition process.

Keywords: birth rate, parenthood, transition, social networks.

\section{Introdução}

A diminuição dos nascimentos é uma tendência prevalente nalguns países europeus, nomeadamente do Sul, incluindo Portugal. Em 2013 o nosso país apresentava um índice sintético de fecundidade de 1,21 crianças por mulher, apenas superior ao da Coreia no universo dos 34 países da OCDE. Em 2015 o índice subiu para 1,3 (equiparando-se ao da Espanha, Grécia e Polónia) mas manteve o país confrontado com um dos mais baixos valores entre os países analisados (OCDE, 2015). A Cova 
da Beira, região sobre a qual se focaliza este estudo, não foge à regra. Sub-região da Beira Interior, é constituída por 3 municípios, Belmonte, Covilhã e Fundão, e contava em 2011 com 90073 habitantes (CLAS, 2012). Desde 2001 até 2011 (data dos últimos censos) tem vindo a apresentar perdas populacionais progressivas, à semelhança das restantes regiões do Interior Centro (Moreira \& Gomes, 2014) provocada não só pela dinâmica migratória, mas também pela diminuição do crescimento natural, e com uma percentagem de jovens inferior à média de Portugal (12,1\% contrapondo com $14,9 \%$ da média nacional) (Gomes \& Moreira, 2014). Uma análise por grupos etários revelou que, entre 2001 e 2010, os efetivos populacionais do grupo dos 0 aos 14 anos se reduziram significativamente nos três Concelhos da Cova da Beira: no Concelho da Covilhã em 1095 indivíduos, no de Belmonte em 193 indivíduos e no Concelho do Fundão a diminuição foi de 714 indivíduos (CLAS, 2012). Em 2016 ocorreram apenas 508 nascimentos na região supracitada (PORDATA, 2017).

Identificar os motivos da diminuição do número de filhos, compreender as mudanças sociais, económicas e culturais, assim como as alterações à estrutura familiar tradicional, torna-se relevante para explicar a tendência atual das sociedades em protelar o processo de transição para a parentalidade. Vários fatores podem ser apontados como influenciadores da transição e adaptação à parentalidade, mas a existência de redes sociais de apoio parece prevalecer, quer na bibliografia de referência, quer nas preocupações que são observadas no dia-a-dia pelos profissionais que lidam diariamente com homens e mulheres que atravessam a nova e complexa missão de serem pais. Os testemunhos dos progenitores observados pelos autores no decurso da sua prática profissional revelam amiúde dúvida sobre os cuidados a prestarem ao bebé ou sobre eventuais problemas que possam surgir, $\mathrm{o}$ medo de falhar, o excesso de informação pouco fidedigna, a denúncia do pouco apoio familiar ou institucional, as parcas condições socioeconómicas e a dificuldade de gerir os rendimentos com a chegada de um novo membro à família. Todas estas declarações confinam numa premissa comum: a inexistência de redes de apoios a quem os pais pudessem recorrer ou a não utilização das mesmas, nas diferentes fases do processo de transição para a parentalidade.

O estudo empírico que dá origem ao presente texto surgiu do interesse em compreender de que forma a existência (e inclua-se nesta noção de "existência" a própria perceção dos pais quanto às redes possíveis / disponíveis e sua composição), o tipo e a utilização dessas redes sociais de apoio influenciariam ou não o mencionado processo de transição para a parentalidade. Ou seja, perceber como as famílias identificam essas redes de apoio, como as usam, como combinam (ou não) o recurso a redes de suporte formais e informais. E, no termo desta análise, avançar 
algumas propostas concernentes ao melhor aproveitamento das redes sociais de apoio enquanto facilitadoras no percurso da transição para a parentalidade. A abordagem produzida combina recursos teóricos e metodológicos oriundos da psicologia e da sociologia, conduzindo a uma análise de natureza correlacional, baseada no método hipotético-dedutivo, que tem como população-alvo as famílias da região portuguesa da Cova da Beira que, à altura da investigação, empreendem ou empreenderam no projeto de construção de uma parentalidade.

\section{Enquadramento teórico}

Os portugueses, tal como os europeus em geral, têm vindo a retardar a natalidade e a diminuir o número de filhos. Como assinala Cunha (2014), Portugal sofreu um reverso na taxa de natalidade e fecundidade, indo estas para valores em que a substituição natural das gerações deixou de ser assegurada. Segundo a autora, esta

alteração está diretamente ligada às mudanças de valores e comportamentos das sociedades modernas, relacionadas não só com as práticas contracetivas, mas também com o peso crescente da figura da mulher, quer na esfera social, quer no mercado de trabalho, e da centralidade e promoção do bem-estar emocional, material e educativo dos filhos na sociedade contemporânea.

Em suma, o comportamento dos portugueses face à fecundidade modificou-se e adaptou-se a uma nova realidade influenciada por alterações profundas a nível político, social e económico. A família tradicional era usualmente formada pela união entre duas pessoas de diferentes sexos, unidas pelo casamento, e pelos seus descendentes diretos, onde existia uma divisão efetiva de papéis e de trabalho entre marido e mulher, com uma hierarquia pré-instituída que conferia estatutos desiguais aos membros da família (Branco \& Pedroso, 2008). Atualmente, dá lugar a novos cenários (famílias monoparentais, reconstituídas por segundas e terceiras uniões, homossexuais, que vivem em união de facto ou resultantes de uma relação jurídica) onde os papéis começam a equiparar-se e os direitos e deveres são cada vez mais partilhados, conferindo à mulher um estatuto de igualdade perante a sociedade e a lei (Ribeiro, Gomes \& Moreira, 2014). A integração desta no mercado de trabalho, na participação ativa na sociedade, no acesso à educação formal e à formação profissional, resultou num adiamento da experiência da maternidade.

Foi a partir da década de 90 que a maternidade nos grupos etários acima dos 30 anos começou, progressivamente, a ganhar terreno. Ao contrário do que sucedeu noutros países europeus, o adiamento da maternidade não foi cúmplice do início do declínio da fecundidade em Portugal, ocorrendo apenas mais tarde e de forma particularmente acentuada. $\mathrm{O}$ padrão de fecundidade das mulheres 
portuguesas nascidas na década de 60 notabilizou-se por uma das mais elevadas proporções de descendências de apenas um filho, e pelo nível mais residual de mulheres que chegaram ao fim do período fértil sem filhos (Frejka, 2008, in Cunha, 2014). Vanessa Cunha defende que a explicação mais forte para a baixa fecundidade na sociedade portuguesa não tem tanto a ver com a vinda do primeiro filho, mas com a vinda do segundo (Sanches \& Manso, s.d.), acrescentando que em Portugal apenas $5 \%$ das mulheres nascidas no início dos anos 60 não tiveram filhos, sendo este o valor mais baixo em termos europeus. No entanto, contrapõe com o facto de Portugal ser o país com valores mais elevados de filhos únicos: $31,9 \%$ das mulheres. Embora tenham sido aplicados programas e incentivos baseados em subsídios e benefícios fiscais, em licenças de maternidade e de paternidade, na flexibilidade laboral, nos cuidados de saúde infantil, não se pode falar na existência de uma política efetiva de natalidade que, aliada ao desemprego de longa duração e apoios sociais cada vez mais precários, culminam na decisão das famílias de não repetirem a gravidez (Cruz, 2011).

De qualquer forma, e independentemente do número de filhos, quando nasce uma criança homens e mulheres têm de construir novos papéis como pai e mãe e de desenvolver um "sistema parental competente" (Relvas \& Lourenço, 2001). Quando se fala em parentalidade, o termo remete para um fenómeno abrangente que inclui a mãe e o pai no desempenho dos seus papéis. Se durante muito tempo foi atribuída exclusivamente à mãe a obrigação e a competência supostamente inata para a criação dos filhos, na sociedade contemporânea o pai tem um papel cada vez mais fundamental na prestação de cuidados e na promoção de um desenvolvimento harmonioso na criança (Leal, 2005), até porque o grande envolvimento das mulheres no campo profissional e social abre espaços para a participação ativa dos progenitores masculinos nos cuidados com os seus filhos (Ribeiro, Gomes, \& Moreira, 2014).

Assim, atualmente, o processo da parentalidade ocorre independentemente do género e carece de maturação e de restruturação psicoafectiva, o que permitirá aos indivíduos responder às necessidades físicas, afetivas e psíquicas dos descendentes (Bayle, 2005). A parentalidade tem de ser construída e trabalhada considerando o passado e as vicissitudes de ambas as partes, para que o verdadeiro processo de vinculação se estabeleça.

Embora não haja consenso em relação ao período exato onde é viável situar a transição para a parentalidade, alguns autores determinam o período que decorre desde a gravidez até aos 18 meses de idade da criança (Nyström \& Öhrling, 2004), sendo os primeiros 12 meses fundamentais na interação futura entre pais/filho(a) (Martins, 2009). Este processo resulta em reorganizações qualitativas da identidade individual e do comportamento externo, com a finalidade de adaptação ao 
papel parental (Cowan \& Hetherington, 1991). No entanto, vários trabalhos mostram que, em casais heterossexuais, este processo não é igual para homens e mulheres. Os autores sugerem uma diferenciação entre os papéis dos cuidadores aquando o nascimento, com as mulheres a tenderem a ter um papel de destaque no cuidado com a criança e a experimentar uma maior rutura nas suas vidas e carreiras quando os seus filhos nascem, em comparação com os homens (Nyström \& Öhrling, 2004). Mercer (2004), na sua teoria "Becaming a Mother" (BAM) que se centra em casais heterossexuais, aborda a transição para a maternidade, que pode ter início antes ou durante a gravidez, com a mulher procurando informações e cuidando de si mesma e do bebé. Relativamente ao pai, esta autora considera que ele não consegue sentir o filho crescer dentro de si, dar à luz e amamentá-lo. Estas características poderão estar na origem de um início mais tardio desta etapa, fortalecendo-se gradualmente a transição após o nascimento e durante o desenvolvimento da criança (Piccinini, Silva, Gonçalves, Lopes \& Tudge, 2004).

Estas experiências de transição para a parentalidade são ainda influenciadas por um conjunto de sistemas intrafamiliares e ambientais (Canavarro \& Pedrosa, 2005), relacionados com as particularidades dos intervenientes (pais e filhos), nomeadamente as características das crianças, divisão de tarefas, qualidade de vida, competências e satisfação parental, relações conjugais, suporte e fatores contextuais (Martins, 2009). Para corroborar esta ideia Murta, Rodrigues, Rosa e Paulo (2012) acrescentam que usufruir de uma relação conjugal satisfatória, ter vivenciado uma relação segura com os próprios cuidadores e ter uma boa qualidade de vida, parecem atuar como fatores de proteção na transição para o nascimento do primeiro filho, contribuindo para a qualidade do cuidado à criança e para o seu desenvolvimento saudável.

Os pais necessitam de aprender e adaptar-se ao novo papel, recorrendo com frequência a vários recursos com o intuito de colmatar as suas necessidades de informação relativamente a esta transição, nomeadamente a familiares, amigos, profissionais de saúde, livros e revistas, televisão, rádio, internet. Estes recursos traduzem-se num suporte social, também designado por rede social de apoio, que pode ser definida como um sistema composto por pessoas, funções e situações que se articulam, trocando elementos entre si e fortalecendo-se reciprocamente (Almeida, 2008). Este apoio pode ser formal se for dado por organizações formais de prestação de assistência (Maximino, Liberman, Frutuoso \& Mendes 2017) ou informal quando inclui a família, os amigos, vizinhos e grupos sociais (MTSS, 2009; Brandão \& Craveirinha, 2011) que por sua vez, providenciam diferentes auxílios à pessoa e à família consoante as necessidades, seja apoio instrumental (compreendido como ajuda financeira, na divisão de responsabilidades e na transmissão de informação ao 
indivíduo), seja emocional (referente ao afeto, aprovação, simpatia, preocupação com o indivíduo) (Portugal, 1995; Dessen \& Braz, 2000).

A revisão bibliográfica aponta como fundamental o papel da solidariedade interpessoal, e da dádiva, na provisão das necessidades sociais dos indivíduos e das famílias. Ela é relevante não só no que concerne à facilitação do acesso aos cuidados de saúde (Portugal, 2005), mas também como mecanismo de compensação face às desigualdades sociais e às limitações do sistema público de bem-estar, ressalvando a ideia de que o apoio proveniente das relações informais tenda a ser mais intenso nas famílias que já ocupam uma posição social mais favorável (Wall, Aboim, Cunha \& Vasconcelos, 2001). Embora pesem os discursos sobre a mutabilidade e o caráter incerto da família nas sociedades modernas (Williams, 2010), assim como a "destruição dos laços tradicionais familiares e das solidariedades" (Clavel, 2004), a verdade é que as redes de relações pessoais continuam a desempenhar um importante papel na vida dos indivíduos e das famílias, como fonte de suporte e de identidade, contribuindo para o seu bem-estar e integração social (Gouveia, 2014).

Quando observadas especificamente na sua relação com a etapa da transição para a parentalidade, as redes sociais de suporte são apontadas como importante mecanismo de auxílio, já que as mesmas podem diminuir as depressões, aumentar a satisfação parental e marital (Martins, 2009) e superar situações complexas, como tornar-se pai/mãe. Dos estudos efetuados (Portugal, 1995; Dessen \& Braz, 2000; Jussani, Serafim \& Silva, 2007; Murta, Rodrigues, Rosa \& Paulo, 2012), as fontes de apoio mais evidenciadas e preferidas pelos pais foram as dos familiares diretos e, no caso das mulheres, um especial destaque para os cônjuges, considerando o seu apoio um fator de proteção fundamental para o bem-estar emocional. Relativamente ao tipo, as orientações sobre os cuidados ao bebé, ajuda financeira, ajuda nas tarefas domésticas e cuidado dos filhos foram mencionadas como ajudas positivas proporcionadas pela rede de apoio (Dessen \& Braz, 2000). No entanto, estas preferências nem sempre são uniformes, sendo frequentemente influenciadas pelas realidades sociais e multiculturais. Por exemplo, nas famílias com baixo nível de literacia, precariedade socioeconómica e afastadas da sua zona de origem, o apoio da rede formal assume um papel fundamental e tem sido percecionado pelos pais como mais útil do que o proporcionado pela rede de apoio informal (Brandão \& Craveirinha, 2011).

Numa sociedade onde o desenvolvimento e o progresso mudaram mentalidades e alteraram toda a estrutura organizacional das famílias em particular, as redes sociais aparecem em especial destaque como a base para a adaptação às mudanças, particularmente na transição para a parentalidade. Extrapolar esta conceção para uma realidade concreta e analisar a relação existente entre a transição 
para a parentalidade e a identificação e utilização de redes sociais de apoio pelos pais, percebendo de que forma a existência, o tipo e a utilização destas redes influenciam essa transição, é o objetivo geral desta pesquisa. No cenário deste objetivo geral, foram considerados três objetivos específicos: (1) analisar se a perceção das famílias quanto à existência e natureza de redes sociais de apoio facilita a sua tomada de decisão quanto a terem filhos; (2) aferir até que ponto o grau de ajuda disponibilizado pelas redes sociais de apoio facilita o processo de transição para a parentalidade; (3) comparar a ajuda disponibilizada pelas redes formais e pelas redes informais de apoio no processo de transição para a parentalidade.

\section{Metodologia}

Amostra

A população-alvo do estudo reporta-se às famílias residentes na região portuguesa da Cova da Beira, que contempla os municípios da Covilhã, Belmonte e Fundão, com pelo menos um filho de 18 meses. A Cova da Beira é caracterizada por uma população com uma taxa bruta de natalidade de $5,6 \%$, valor inferior à média nacional (que é de 7,9\%o). Nesta região, a dimensão média da família situa-se nos 2,4 indivíduos (PORDATA, 2015). No processo de construção da amostra optou-se por um plano de amostragem não probabilístico por amostragem acidental, contando-se com a colaboração de vários infantários da região na identificação das famílias com as características requeridas para a participação no estudo A amostra construída é composta por 138 progenitores, 72 mães com idades compreendidas entre os $20 \mathrm{e}$ 43 anos e 66 pais com idades entre 22 e 56 anos. Reportando à idade em que foram mães e pais pela primeira vez, o intervalo de idades com maior percentagem para o sexo feminino (21,8\%) situa-se entre os 25 e os 30 anos, e para o sexo masculino, entre os 30 e 35 anos (23,2\%). São famílias predominantemente nucleares, cujos progenitores se encontram unidos por casamento $(60,9 \%)$ ou união de facto $(31,2 \%)$. Apenas 6,5\% são solteiros e os restantes 1,4\% são separados ou divorciados. Relativamente à descendência, 51,4\% das famílias têm maioritariamente um filho, 39,9\% dois filhos e 4,3\% três filhos. As únicas duas famílias da amostra com mais de 3 filhos são famílias reconstituídas, com filhos de anteriores uniões. Considerando as habilitações literárias, a maioria tem, pelo menos, a escolaridade obrigatória, sendo que $27,5 \%$ da amostra completou o $12^{\circ}$ ano, $37,5 \%$ a licenciatura, $9,4 \%$ o mestrado e $1,4 \%$ o doutoramento. A grande percentagem da amostra $(89,9 \%)$ encontra-se empregada, auferindo rendimentos mensais (agregado) maioritariamente situados entre os 550 e os 1990 euros $(63,1 \%)$, repartindo-se da seguinte forma: 31,9\% 
entre 550 e 1099 euros e 31,2\% entre 1100 e 1999 euros. Relativamente aos 124 indivíduos que estão no mercado de trabalho, e relativamente à profissão que exercem, $41,9 \%$ têm profissões técnico-científicas e são quadros de pequenas e médias empresas, $25,8 \%$ são empregados dos serviços e uma percentagem também significativa $(21,8 \%)$ exerce funções no operariado fabril, transportes, construção civil e comunicações. Apenas uma percentagem muito pequena ( $0,8 \%)$ se insere no grande patronato, gestores de grandes empresas e profissões liberais e 1,6\% nos trabalhadores manuais por conta própria, sobretudo agricultores.

\section{Instrumento de recolha}

Baseando-nos nos trabalhos que sugerem que os processos de transição para a parentalidade não são iguais para homens e mulheres, foram elaborados dois questionários, que possibilitaram a recolha de informação para o estudo. O questionário englobou várias questões que permitiram a operacionalização das diferentes variáveis, não só as que caracterizam a população mas também as dependentes e independentes.

Variável dependente: Transição para a parentalidade

Optou-se pela utilização de escalas de Likert, por ser o instrumento mais utilizado para medir atitudes (Rodrigues, 1991). Construíram-se duas escalas com 5 níveis (Concordo totalmente, Concordo, Sem opinião, Discordo, Discordo completamente), uma adaptada à mãe e outra ao pai, com indicadores referentes ao processo de transição materna e paterna, já que os mesmos ocorrem de forma distinta. Em cada uma delas contemplaram-se 6 dimensões que, baseadas na fundamentação teórica (Canavarro \& Pedrosa, 2005; Martins, 2009), podem influenciar as atitudes e consequentemente o comportamento dos pais face à transição para a parentalidade: Características das crianças, Divisão de tarefas, Qualidade de vida, Competências e Satisfação Parental, Relação Conjugal, Suporte e Fatores Contextuais. Os indicadores das 6 dimensões foram distribuídos por 36 itens (6 para cada dimensão), como apresentado no quadro 1 e 2 . Foram elaborados 18 itens com formulação positiva e 18 itens na negativa para evitar enviesamentos nas respostas. Os scores obtidos traduzem o tipo de atitude face à transição para a parentalidade, considerando o grau de concordância com as afirmações apresentadas e foram agrupados com base nos scores mínimos e máximos possíveis de obter em cada dimensão e de acordo com os valores atribuídos a cada item. Para facilitar o cruzamento de dados na análise inferencial e diminuir a dispersão dos resultados, optou-se por definir três tipos de atitudes: menos favoráveis (scores entre os 36-72), moderadamente favoráveis (entre os 73-143) e mais favoráveis (entre os 144-180). 
Quadro 1 Distribuição dos itens relativos à escala da transição para a parentalidade pelas diferentes dimensões (MÃE)

\begin{tabular}{|c|c|}
\hline Itens maternos & Dimensões \\
\hline $\begin{array}{l}\text { 1. Sinto-me com competências para cuidar tanto de uma menina como de um menino } \\
\text { 2. Sei cuidar tão bem de um recém-nascido como de uma criança de um ano } \\
\text { 3. O choro do/da meu/minha filho/filha deixa-me sempre muito ansiosa } \\
\text { 4. Gostava que o/a meu/minha filho/filha tivesse um temperamento mais fácil } \\
\text { 5. Cuidar de uma criança pequena é muito exigente para mim } \\
\text { 6. Se se elogiam muito as crianças, elas tornam-se vaidosas }\end{array}$ & 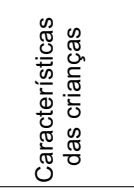 \\
\hline $\begin{array}{l}\text { 7. Eu divido as tarefas domésticas com o meu marido/ companheiro } \\
\text { 8. O meu marido/ companheiro ajuda-me mais em casa desde o nascimento } \\
\text { do/da nosso/nossa filho/filha } \\
\text { 9. Sinto-me sobrecarregada com as tarefas domésticas } \\
\text { 10. O meu marido/ companheiro não me ajuda nos cuidados ao bebé } \\
\text { 11. Quando nasce uma criança é fundamental que o casal partilhe todas as tarefas, } \\
\text { quer as da lida da casa, quer as dos cuidados com o bebé } \\
\text { 12. Tenho tempo de sobra para me dedicar ao/à meu/minha filho/filha }\end{array}$ & 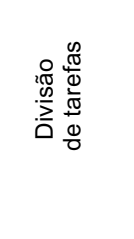 \\
\hline $\begin{array}{l}\text { 13. A minha vida social não sofreu grandes alterações com o nascimento } \\
\text { do/da meu/minha filho/filha } \\
\text { 14. Saio menos com os amigos desde que o/a meu/minha filho/filha nasceu } \\
\text { 15. O meu marido/companheiro sai muitas vezes sem mim } \\
\text { 16. Deixei de ter tempo para cuidar de mim desde o nascimento do/da meu/minha } \\
\text { filho/filha } \\
\text { 17. Tive de desistir de muitas coisas de que gosto para tomar conta do/da meu/minha } \\
\text { filho/filha } \\
\text { 18. Gosto de sair de casa com o/a meu/minha filho/ filha }\end{array}$ & $\begin{array}{l}\frac{0}{0} \\
\frac{\pi}{\pi} \\
\frac{\pi}{0} \\
\frac{0}{0} \\
\frac{0}{3} \\
0 \\
0\end{array}$ \\
\hline $\begin{array}{l}\text { 19. A experiência da amamentação é/foi gratificante } \\
\text { 20. Sinto-me orgulhosa de ser mãe } \\
\text { 21. A experiencia que vivi como filha ajuda-me no papel de mãe } \\
\text { 22. Sinto-me deprimida desde que fui mãe } \\
\text { 23. Tenho receio de não estar a fazer um bom trabalho como mãe } \\
\text { 24. Presto bons cuidados ao/à meu/minha filho/filha }\end{array}$ & 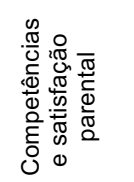 \\
\hline $\begin{array}{l}\text { 25. A relação como o meu marido/companheiro melhorou desde a gravidez } \\
\text { 26. Tenho mais prazer na relação sexual depois de ser mãe } \\
\text { 27. Discuto mais com o meu marido/companheiro desde o nascimento do/da } \\
\text { nosso/nossa filho/filha } \\
\text { 28. Não tenho tempo para o meu marido/ companheiro } \\
\text { 29. Desde que o meu/minha filho/filha nasceu, eu e o meu marido/ companheiro } \\
\text { não temos qualquer privacidade } \\
\text { 30. Tem sido fácil lidar com as exigências colocadas ao casal pela criança }\end{array}$ & 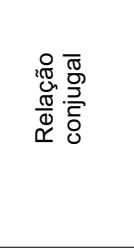 \\
\hline $\begin{array}{l}\text { 31. Posso contar com o meu marido/ companheiro para cuidar de mim e do meu } \\
\text { filho/filha } \\
\text { 32. Sinto-me apoiada pela minha família desde o início da gravidez } \\
\text { 33. Tive acesso a toda a informação que necessitava para prestar bons cuidados } \\
\text { ao meu filho/filha } \\
\text { 34. O meu marido/ companheiro ignora os meus sentimentos } \\
\text { 35. O interesse que as pessoas demonstram pelo/a meu/minha filho/filha é exagerado } \\
\text { 36. Não tenho a quem recorrer quando necessito de apoio no papel de mãe }\end{array}$ & 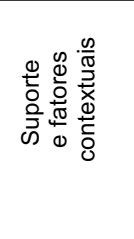 \\
\hline
\end{tabular}

Fonte: Elaboração própria. 
Quadro 2 Distribuição dos itens relativos à escala de transição para a parentalidade pelas diferentes dimensões (PAI)

\begin{tabular}{|c|c|}
\hline Itens paternos & Dimensões \\
\hline $\begin{array}{l}\text { 1. Desde o nascimento do/da meu/minha filho/filha que eu cuido dele de forma ativa } \\
\text { 2. Sinto-me tão à vontade para cuidar de meninos como de meninas } \\
\text { 3. O choro do/da meu/ minha filho/filha deixa-me sempre muito ansioso } \\
\text { 4. Gostava que o/a meu/minha filho/filha tivesse um temperamento mais fácil } \\
\text { 5. Cuidar de uma criança pequena é muito exigente para mim } \\
\text { 6. Se se elogiam muito as crianças, elas tornam-se vaidosas }\end{array}$ & 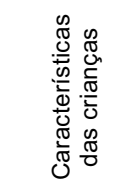 \\
\hline $\begin{array}{l}\text { 7. Eu divido as tarefas domésticas com a minha esposa/companheira } \\
\text { 8. Desde que a mãe regressou ao trabalho sinto-me mais autónomo nos cuidados } \\
\text { ao/à meu/minha filho/filha } \\
\text { 9. A mãe tem mais competências para cuidar do bebé } \\
\text { 10. Sinto um peso acrescido sobre mim e na responsabilidade que tenho em sustentar } \\
\text { a família desde que o/a meu/minha filho/filha nasceu } \\
\text { 11. Quando nasce uma criança é fundamental que o casal partilhe todas as tarefas, } \\
\text { quer as da lida da casa, quer as dos cuidados com o bebé } \\
\text { 12. Tenho tempo de sobra para me dedicar ao/à meu/minha filho/filha }\end{array}$ & 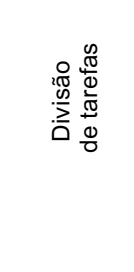 \\
\hline $\begin{array}{l}\text { 13. A minha vida social não sofreu grandes alterações com o nascimento do/da } \\
\text { meu /minha filho/filha } \\
\text { 14. Saio menos com os amigos desde que o/a meu /minha filho/filha nasceu } \\
\text { 15. Deixei de ter tempo para mim desde que o/a meu/minha filho/filha nasceu } \\
\text { 16. Ser pai exige que abdiquemos de algum bem-estar } \\
\text { 17. Tive de desistir de muitas coisas de que gosto para tomar conta do/da meu/minha } \\
\text { filho/filha } \\
\text { 18. Gosto de sair de casa com o/a meu/minha filho/filha }\end{array}$ & $\begin{array}{l}\frac{0}{0} \frac{\pi}{\pi} \\
\frac{\pi}{0} \\
\frac{0}{\frac{0}{2}} \\
\frac{\pi}{2} \frac{0}{0} \\
0\end{array}$ \\
\hline $\begin{array}{l}\text { 19. Gostei muito que a minha esposa/ companheira amamentasse/amamente } \\
\text { o/a meu/minha filho/filha } \\
\text { 20. Sinto-me orgulhoso de ser pai } \\
\text { 21. A experiencia que vivi como filho ajuda-me no papel de pai } \\
\text { 22. Sinto-me ansioso desde que fui pai } \\
\text { 23. Tenho receio de não estar a fazer um bom trabalho como pai } \\
\text { 24. Presto bons cuidados ao/à meu /minha filho/filha }\end{array}$ & 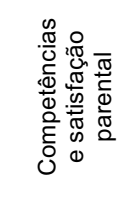 \\
\hline $\begin{array}{l}\text { 25. A relação como a minha esposa/companheira melhorou desde a gravidez } \\
\text { 26. A frequência com que temos relações sexuais não se alterou com o nascimento } \\
\text { do/da meu/minha filho/filha } \\
\text { 27. Discuto mais com a minha esposa/companheira desde o nascimento do bebé } \\
\text { 28. A minha esposa/ companheira não tem tempo para mim } \\
\text { 29. Desde que o/a meu/minha filho/filha nasceu, eu e a minha esposa/ companheira } \\
\text { não temos qualquer privacidade } \\
\text { 30. Tem sido fácil lidar com as exigências colocadas ao casal pela criança }\end{array}$ & 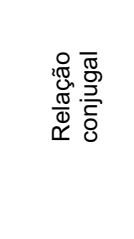 \\
\hline $\begin{array}{l}\text { 31. Tenho capacidade para fazer face aos custos associados ao nascimento de um } \\
\text { filho/filha } \\
\text { 32. Tive acesso a toda a informação que necessitava para prestar bons cuidados } \\
\text { ao /à meu/minha filho/filha } \\
\text { 33. Sinto-me apoiado pela minha família desde o nascimento do/da meu/minha filho/filha } \\
\text { 34. Sinto-me relegado para segundo plano desde que o/a meu/minha filho/filha nasceu } \\
\text { 35. Gostava que as pessoas estivessem tão interessadas em mim como estão no/na } \\
\text { meu/minha filho/filha } \\
\text { 36. Não tenho a quem recorrer quando necessito de apoio no papel de pai }\end{array}$ & 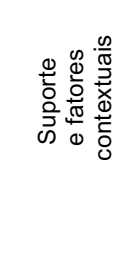 \\
\hline
\end{tabular}

Fonte: Elaboração própria. 
Ensaiou-se a validação das escalas a partir da amostra final. Na aferição da qualidade das correlações entre as variáveis através do método Kaiser-Meyer-Olkin obteve-se para a escala materna o valor de 0,536 e para a paterna o valor de 0,526 , revelando ambas uma correlação má. Também no método de Extração das Componentes Principais e Método de Rotação Varimax com Normalização de Kaiser, verificou-se que, para a escala da mãe apenas 13 fatores apresentam variância explicada superior a 1 e mesmo retendo esses 13 fatores, a soma destes só explica 73,6\% da variância dos dados, quando deveria explicar quase a sua totalidade. Para a escala do pai o cenário é idêntico. No método da extração de componentes principais, apenas 12 fatores apresentam variância explicada superior a 1 e a soma deles explicam $72,5 \%$ da variância. Relativamente à associação das variáveis aos fatores extraídos através do método Varimax para as duas escalas, observou-se que a maioria tinha um peso inferior a 0,5 , não havendo deste modo associação. Os resultados obtidos ficaram abaixo dos valores necessários para uma validação efetiva das escalas, o que, todavia, não retira pertinência à análise produzida.

\section{Variável independente: Rede Social}

A variável foi operacionalizada tendo em conta o tipo e a fonte de apoio, tendo sido utilizada, além de questões abertas e fechadas, uma Escala de Avaliação do Apoio Social à Família (quadro 3). Esta Escala, adaptada por Coutinho (2004) do original Family Support Scale de Dunst, Jenkins and Trivette (1984), destina-se a aferir a quantidade de apoio dispensada pelas diferentes fontes. Foram realizadas alterações na questão 16 para facilitar a compreensão da mesma, passando de "Programa de intervenção precoce" para "Programas de apoio estatais (Programa de intervenção precoce, apoios sociais)". Os dezanove itens da Escala estão distribuídos por cinco subescalas: Família (itens 1, 2, 3, 4, 5 e 8), Relações Próximas (itens 6, 7, 9, 10 e 11), Grupos Sociais (itens 12,13 e 14), Profissionais (itens 15 e 18) e Grupos Profissionais (itens 16,17 e 19). A escala possui uma parcela de exclusão (Não Disponível) cotada com 0 . As restantes parcelas são cotadas de 1 a 5 correspondendo ao nível de apoio dado (1- Não ajuda, 2- Por vezes ajuda, 3- geralmente ajuda, 4- ajuda muito, 5- ajuda imenso).

Os scores obtidos traduzem o grau de apoio social, considerando o grau de concordância com as afirmações apresentadas. Definiram-se três graus de ajuda: Inexistente a Reduzido (score entre os 0-38), Moderado (entre os 39-75) e Elevado (76-95), valores calculados para a rede total (agregação da rede informal com a rede formal). A Rede Informal agrega as subescalas "Família", "Relações próximas" e "Grupos sociais", com valores de 0-28 (Inexistente a Reduzido), 29-55 (Moderado) e 56-70 (Elevado) e a Rede Formal agrega as subescalas "Profissionais" e "Grupos 
Quadro 3 Escala de Avaliação Do Apoio Social à Família

\begin{tabular}{|c|c|c|c|c|c|c|}
\hline \multirow{2}{*}{$\begin{array}{c}\text { Que ajuda lhe têm dado cada uma das } \\
\text { seguintes pessoas ou grupos na tarefa } \\
\text { de criar o(s) seu(s) filho(s) }\end{array}$} & \multirow{2}{*}{$\begin{array}{c}\text { Não } \\
\text { disponível }\end{array}$} & \multicolumn{5}{|c|}{ Disponível } \\
\hline & & $\begin{array}{l}\text { Não } \\
\text { ajuda }\end{array}$ & $\begin{array}{c}\text { Por vezes } \\
\text { ajuda }\end{array}$ & $\begin{array}{l}\text { Geralmente } \\
\text { ajuda }\end{array}$ & $\begin{array}{l}\text { Ajuda } \\
\text { muito }\end{array}$ & $\begin{array}{l}\text { Ajuda } \\
\text { imenso }\end{array}$ \\
\hline \multicolumn{7}{|l|}{ 1. Meus pais } \\
\hline \multicolumn{7}{|l|}{$\begin{array}{l}\text { 2. Os pais do meu/ minha cônjuge } \\
\text { (ou companheiro/a) }\end{array}$} \\
\hline \multicolumn{7}{|l|}{ 3. Meus parentes } \\
\hline \multicolumn{7}{|l|}{$\begin{array}{l}\text { 4. Os parentes do meu/minha cônjuge } \\
\text { (ou companheiro/a) }\end{array}$} \\
\hline \multicolumn{7}{|l|}{ 5. Cônjuge (ou companheiro/a) } \\
\hline \multicolumn{7}{|l|}{ 6. Meus amigos } \\
\hline \multicolumn{7}{|l|}{$\begin{array}{l}\text { 7. Os amigos do meu/minha cônjuge } \\
\text { (ou companheiro/a) }\end{array}$} \\
\hline \multicolumn{7}{|l|}{ 8. Os meus filhos } \\
\hline \multicolumn{7}{|l|}{ 9. Vizinhos/as } \\
\hline \multicolumn{7}{|l|}{ 10. Outros pais } \\
\hline \multicolumn{7}{|l|}{ 11. Colegas de trabalho } \\
\hline \multicolumn{7}{|l|}{ 12. Grupos de pais } \\
\hline \multicolumn{7}{|l|}{$\begin{array}{l}\text { 13. Grupos sociais (associações) } \\
\text { /Clubes }\end{array}$} \\
\hline \multicolumn{7}{|l|}{ 14. Membros da igreja/ padres } \\
\hline \multicolumn{7}{|l|}{ 15. Médico/a de família ou da criança } \\
\hline \multicolumn{7}{|l|}{$\begin{array}{l}\text { 16.Programas de apoio estatais } \\
\text { (Programa de intervenção precoce, } \\
\text { apoios sociais) }\end{array}$} \\
\hline \multicolumn{7}{|l|}{ 17. Creche/ jardim-de-infância } \\
\hline \multicolumn{7}{|l|}{$\begin{array}{l}\text { 18. Profissionais (Assistentes sociais, } \\
\text { Terapeutas, Educadores, Enfermeiros) }\end{array}$} \\
\hline $\begin{array}{l}\text { 19. Serviços (serviços sociais, } \\
\text { serviços de saúde) }\end{array}$ & & & & & & \\
\hline
\end{tabular}

Fonte: Carl Dunst, Vicki JenKiins e Carol M. Trivette, adaptado por Coutinho (2004).

profissionais" com valores de 0-10 (Inexistente a Reduzido), 11-19 (Moderado) e 20-25 (Elevado).

\section{Procedimento}

Foram distribuídos 288 questionários, recolhidos 145 e validados 138. Antes de se aplicar o questionário no campo foram cumpridas as diligências que formalizaram e legitimaram todo o processo de colheita de dados. Em primeiro lugar, foi solicitada em cada estabelecimento uma autorização para a realização do estudo. Neste 
pedido estava explicitado o objetivo do estudo, os participantes e quais os recursos necessários. A cada participante foi pedida a assinatura de uma declaração de consentimento informado, assumindo-se para com eles a confidencialidade das respostas fornecidas. Os questionários foram devidamente identificados e acompanhados por instruções definidas e notas explicativas, para que os inquiridos tomassem conhecimento do pretendido.

\section{Resultados}

Foram questionados os progenitores sobre as motivações de quererem ou não quererem ter mais filhos. Considerando o número de respostas obtidas (44 para o sime 32 para o não) a justificação maioritária dada por ambos (mãe e pai) para o não quererem foi a de razões financeiras $(40,6 \%)$. No lado oposto, a justificação maioritária para o desejo de ter mais filhos recaiu no facto de ser um projeto de vida ou pessoal (52,3\%). Estas motivações poderão estar relacionadas com as vivências dos progenitores, refletidas nas atitudes face à transição para a parentalidade. No que concerne a essas atitudes, verificou-se pelos scores obtidos que as mães e os pais (tabela 1), perante as particularidades do exercício da parentalidade e durante todo o processo de adaptação, revelam uma atitude moderadamente favorável. Os scores variam para os pais entre os 96 e 155 e para as mães entre os 96 e 163.

Quadro 4 Scores materno e paterno na transição para a parentalidade

\begin{tabular}{l|l|c|c|c|c|c|c}
\hline \multirow{2}{*}{ Transição para a parentalidade } & \multicolumn{4}{c}{ Tipo de atitude } \\
\cline { 3 - 7 } & & \multicolumn{2}{|c|}{ Menos } & \multicolumn{2}{c}{ Moderadamente } & \multicolumn{2}{c}{ Mais } \\
\cline { 3 - 7 } & & $\mathrm{n}$ & $\%$ & $\mathrm{n}$ & $\%$ & $\mathrm{n}$ & $\%$ \\
\hline \multirow{5}{*}{ Score Materno } & Características das crianças & - & - & 42 & 58,3 & 30 & 41,7 \\
& Divisão de tarefas & - & - & 58 & 80,6 & 14 & 19,4 \\
& Qualidade de vida & - & - & 64 & 88,9 & 8 & 11,1 \\
& Competências e satisfação parental & - & - & 12 & 16,7 & 60 & 83,3 \\
& Relação conjugal & 3 & 4,2 & 61 & 84,7 & 8 & 11,1 \\
& Suporte e fatores contextuais & - & - & 24 & 33,3 & 48 & 66,7 \\
\hline \multirow{5}{*}{ Score Paterno } & Características das crianças & - & - & 47 & 71,2 & 19 & 28,8 \\
& Divisão de tarefas & - & - & 60 & 90,9 & 6 & 9,1 \\
& Qualidade de vida & 4 & 6,1 & 55 & 83,3 & 7 & 10,6 \\
& Competências e satisfação parental & - & - & 15 & 22,7 & 51 & 77,3 \\
& Relação conjugal & 2 & 3,0 & 49 & 74,3 & 15 & 22,7 \\
& Suporte e fatores contextuais & - & - & 31 & 47,0 & 35 & 53,0 \\
\hline
\end{tabular}

Fonte: Elaboração própria 
Quadro 5 Grupos de scores Rede Social

\begin{tabular}{|c|c|c|c|c|c|c|c|c|c|c|}
\hline \multirow{3}{*}{\multicolumn{3}{|c|}{ Apoio Social }} & \multicolumn{6}{|c|}{ Grau de ajuda } & \multirow{2}{*}{\multicolumn{2}{|c|}{ Total }} \\
\hline & & & \multicolumn{2}{|c|}{$\begin{array}{l}\text { Inexistente a } \\
\text { Reduzido }\end{array}$} & \multicolumn{2}{|c|}{ Moderado } & \multicolumn{2}{|c|}{ Elevado } & & \\
\hline & & & $\mathrm{n}$ & $\%$ & $\mathrm{n}$ & $\%$ & $\mathrm{~N}$ & $\%$ & $\mathrm{n}$ & $\%$ \\
\hline \multirow{5}{*}{ 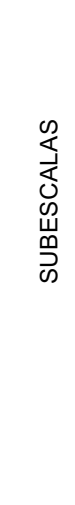 } & Famíliaa & $\begin{array}{l}\text { Mãe } \\
\text { Pai } \\
\text { Subtotal }\end{array}$ & $\begin{array}{r}14 \\
7 \\
21\end{array}$ & $\begin{array}{r}10,1 \\
5,1 \\
15,2\end{array}$ & $\begin{array}{l}47 \\
52 \\
99\end{array}$ & $\begin{array}{l}34,1 \\
37,7 \\
71,8\end{array}$ & $\begin{array}{r}11 \\
7 \\
18\end{array}$ & $\begin{array}{r}7,9 \\
5,1 \\
13,0\end{array}$ & $\begin{array}{r}72 \\
66 \\
138\end{array}$ & $\begin{array}{r}52,1 \\
47,9 \\
100,0\end{array}$ \\
\hline & $\begin{array}{l}\text { Relações } \\
\text { próximas }^{b}\end{array}$ & $\begin{array}{l}\text { Mãe } \\
\text { Pai } \\
\text { Subtotal }\end{array}$ & $\begin{array}{r}58 \\
54 \\
112\end{array}$ & $\begin{array}{l}42,1 \\
39,1 \\
81,2\end{array}$ & $\begin{array}{l}14 \\
12 \\
26\end{array}$ & $\begin{array}{r}10,1 \\
8,7 \\
18,8\end{array}$ & $\begin{array}{l}- \\
-\end{array}$ & $\begin{array}{l}- \\
- \\
-\end{array}$ & $\begin{array}{r}72 \\
66 \\
138\end{array}$ & $\begin{array}{r}52,1 \\
47,9 \\
100,0\end{array}$ \\
\hline & $\begin{array}{l}\text { Grupos } \\
\text { sociais }^{c}\end{array}$ & $\begin{array}{l}\text { Mãe } \\
\text { Pai } \\
\text { Subtotal }\end{array}$ & $\begin{array}{r}71 \\
65 \\
136\end{array}$ & $\begin{array}{l}51,5 \\
47,1 \\
98,6\end{array}$ & $\begin{array}{l}1 \\
1 \\
2\end{array}$ & $\begin{array}{l}0,7 \\
0,7 \\
1,4\end{array}$ & $\begin{array}{l}- \\
- \\
-\end{array}$ & $\begin{array}{l}- \\
- \\
-\end{array}$ & $\begin{array}{r}72 \\
66 \\
138\end{array}$ & $\begin{array}{r}52,1 \\
47,9 \\
100,0\end{array}$ \\
\hline & Profissionais $^{d}$ & $\begin{array}{l}\text { Mãe } \\
\text { Pai } \\
\text { Subtotal }\end{array}$ & $\begin{array}{l}33 \\
31 \\
64\end{array}$ & $\begin{array}{l}23,9 \\
22,5 \\
46,4\end{array}$ & $\begin{array}{l}23 \\
25 \\
48\end{array}$ & $\begin{array}{l}16,6 \\
18,1 \\
34,7\end{array}$ & $\begin{array}{l}16 \\
10 \\
26\end{array}$ & $\begin{array}{r}11,6 \\
7,3 \\
18,9\end{array}$ & $\begin{array}{r}72 \\
66 \\
138 \\
\end{array}$ & $\begin{array}{r}52,1 \\
47,9 \\
100,0\end{array}$ \\
\hline & $\begin{array}{l}\text { Grupos } \\
\text { profissionais }^{e}\end{array}$ & $\begin{array}{l}\text { Mãe } \\
\text { Pai } \\
\text { Subtotal }\end{array}$ & $\begin{array}{l}35 \\
31 \\
66\end{array}$ & $\begin{array}{l}25,3 \\
22,5 \\
47,8\end{array}$ & $\begin{array}{l}35 \\
32 \\
67\end{array}$ & $\begin{array}{l}25,3 \\
23,3 \\
48,6\end{array}$ & $\begin{array}{l}2 \\
3 \\
5\end{array}$ & $\begin{array}{l}2,1 \\
1,5 \\
3,6\end{array}$ & $\begin{array}{r}72 \\
66 \\
138\end{array}$ & $\begin{array}{r}52,1 \\
47,9 \\
100,0\end{array}$ \\
\hline \multirow{3}{*}{ 㞻 } & $\begin{array}{l}\text { Rede informal } \\
(a+b+c)\end{array}$ & $\begin{array}{l}\text { Mãe } \\
\text { Pai } \\
\text { Subtotal }\end{array}$ & $\begin{array}{l}43 \\
37 \\
80\end{array}$ & $\begin{array}{l}31,2 \\
26,8 \\
58,0\end{array}$ & $\begin{array}{l}29 \\
29 \\
58\end{array}$ & $\begin{array}{l}21,0 \\
21,0 \\
42,0\end{array}$ & $\begin{array}{l}- \\
-\end{array}$ & $\begin{array}{l}- \\
- \\
-\end{array}$ & $\begin{array}{r}72 \\
66 \\
138\end{array}$ & $\begin{array}{r}52,1 \\
47,9 \\
100,0\end{array}$ \\
\hline & $\begin{array}{l}\text { Rede formal } \\
(d+e)\end{array}$ & $\begin{array}{l}\text { Mãe } \\
\text { Pai } \\
\text { Subtotal }\end{array}$ & $\begin{array}{l}32 \\
25 \\
57\end{array}$ & $\begin{array}{l}23,2 \\
18,1 \\
41,3\end{array}$ & $\begin{array}{l}36 \\
37 \\
73\end{array}$ & $\begin{array}{l}26,1 \\
26,8 \\
52,9\end{array}$ & $\begin{array}{l}4 \\
4 \\
8\end{array}$ & $\begin{array}{l}2,9 \\
2,9 \\
5,8\end{array}$ & $\begin{array}{r}72 \\
66 \\
138\end{array}$ & $\begin{array}{r}52,1 \\
47,9 \\
100,0\end{array}$ \\
\hline & Rede total & $\begin{array}{l}\text { Mãe } \\
\text { Pai } \\
\text { Subtotal }\end{array}$ & $\begin{array}{l}40 \\
36 \\
76\end{array}$ & $\begin{array}{l}29,0 \\
26,1 \\
55,1\end{array}$ & $\begin{array}{l}32 \\
30 \\
62\end{array}$ & $\begin{array}{l}23,2 \\
21,8 \\
44,9\end{array}$ & - & $\begin{array}{l}- \\
- \\
-\end{array}$ & $\begin{array}{r}72 \\
66 \\
138\end{array}$ & $\begin{array}{r}52,1 \\
47,9 \\
100,0\end{array}$ \\
\hline
\end{tabular}

Fonte: Elaboração própria.

Os pais obtiveram scores representativos de uma atitude menos favorável tanto para o subgrupo da relação conjugal como para o subgrupo da qualidade de vida e as mães apenas a apresentam no caso da relação conjugal. Relativamente ao subgrupo "Competência e satisfação parental", as mães têm uma percentagem maior de scores coincidentes com uma atitude mais favorável, que pode estar relacionada com a construção da confiança sobre as suas competências e auto eficiência nos cuidados ao bebé, em comparação com os pais. Relativamente às redes de apoio e considerando as fontes de apoio, $86,2 \%$ da amostra refere ter familiares próximos a quem recorrer, sendo que a grande maioria refere os avós das crianças como recurso principal. Todos os familiares estão englobados no que se denominou por "Rede informal", o que à partida poderia conduzir à ideia de que seria esta a que fornece maior grau de ajuda. Todavia, quando se agrupam os scores e se compara o grau de apoio social prestado pelas "redes informais" versus "redes formais" (quadro 5), é a rede 
formal aquela que apresenta um score mais elevado para o grau de ajuda. Pese embora apenas $58 \%$ da amostra referir recorrer à ajuda de profissionais para informação ou apoio técnico.

Considerando o tipo de apoio reportável aos familiares e amigos, a maior percentagem referiu ser de natureza emocional/afetivo aquele que mais receberam e o que gostariam de receber. Em relação aos profissionais, o tipo de apoio mencionado como o mais recebido foi o informativo, que coincide também com o que gostariam de receber.

Tendo em conta o objetivo do trabalho, cruzaram-se variáveis para perceber a influência de cada uma delas, utilizando para isso o teste do teste Qui-quadrado $\left(X^{2}\right)$ e níveis de significância de a $\alpha=0,05$, a partir do qual se aceita a hipótese nula no que concerne à relação entre o apoio fornecido pelas redes sociais e a tomada de decisão das famílias em terem filhos.

O apoio fornecido pelas redes sociais influencia a tomada de decisão das famílias em terem filhos.

Relativamente à fonte de apoio: para a família obteve-se um $\mathrm{X}^{2}=0,347$ e a $\alpha=0,841$, para os amigos obteve-se um $X^{2}=5,281$ e $\alpha=0,071$ e para os profissionais obtevese um $X^{2}=3,431$ e $\alpha=0,180$, não existindo relação estatística.

Considerando o tipo de apoio: para a família obteve-se $X^{2}=38,985$ e $\alpha=0,000$, para os amigos $X^{2}=24,076$ e $\alpha=0,000$ e para os profissionais $X^{2}=27,104$ e $\alpha=0,000$. Observa-se que existe relação estatística altamente significativa uma vez que a <,001.

A classe social e o rendimento líquido auferido pelas famílias influenciamo desejo dos pais de terem mais filhos

Considerando a classe social obteve-se um $X^{2}=4,517$ e $\alpha=0,921$, não existindo relação estatística significativa entre as variáveis. Para o rendimento mensal obteve-se $X^{2}=3,188$ e $\alpha=0,922$, também sem relação estatística significativa entre as variáveis.

\section{A estrutura familiar influencia a transição para a parentalidade}

Para o score total da transição para a parentalidade obteve-se um $X^{2}=121,794$ e $\alpha=0,835$, para o score materno, um $X^{2}=134,317$ e $\alpha=0,018$ e para o score paterno, $X^{2}=23,758$ e $\alpha=0,942$. Conclui-se que, quer para o score total quer para o score paterno, não existe relação estatística significativa uma vez que a $>0,05$, mas para o score materno existe uma relação estatística significativa.

Reportando agora aos objetivos específicos, aplicou-se o teste ao Coeficiente de Correlação de Spearman ( $\rho S$ ) e o mesmo nível de significância, obtendo-se os 
seguintes resultados estatísticos:

Objetivo 1: Analisar se a perceção das famílias quanto à existência de redes sociais de apoio facilita a tomada de decisão das famílias em terem filhos

Obteve-se um $\rho S=-0,164$ e $\alpha=0,054$. Perante estes valores, não há evidências estatísticas para se afirmar que de facto a existência de redes sociais de apoio e a decisão das famílias de terem filhos estão relacionadas $(\alpha>0,05)$.

Objetivo 2: Analisar se o grau de ajuda disponibilizado pelas redes sociais de apoio facilita o processo de transição para a parentalidade

Obteve-se um $\rho S=0,290$ e $\alpha=0,000$. Estes resultados revelam que existem evidências estatísticas para se afirmar que o grau de ajuda disponibilizado pelas redes sociais de apoio e o processo de transição para a parentalidade estão relacionados $(\alpha<, 05)$. Como $\rho S$ é diferente de 0 e positivo, pode-se ainda afirmar que existe uma associação linear pequena e positiva entre as variáveis.

Objetivo 3: Analisar se a ajuda disponibilizada pelas redes informais de apoio é mais facilitadora no processo de transição para a parentalidade do que a ajuda disponibilizada pelas redes formais de apoio

Obteve-se para a correlação entre a "Rede informal" e o "Grau de ajuda da rede social" $\rho S=0,304$ e $\alpha=0,000$. Perante estes valores, existem evidências estatísticas para se afirmar que as duas variáveis estão relacionadas $(\alpha<, 05)$. Como $\rho S$ é diferente de 0 e positivo, existe uma associação linear moderada e positiva entre as mesmas.

Relativamente ao grau de ajuda disponibilizado pela rede formal e o processo de transição para a parentalidade obteve-se $\rho S=0,107$ e $\alpha=0,107$. Deste modo existem evidências estatísticas para se afirmar que as duas variáveis não estão relacionadas $(\alpha>0,05)$.

\section{Conclusões e propostas}

Este trabalho teve como objetivo compreender de que forma a existência, o tipo e a utilização das redes sociais de apoio influenciariam ou não a transição para a parentalidade. Este objectivo foi cumprido através da análise da relação entre a existência e identificação dessas redes e a sua utilização por parte dos pais residentes na região portuguesa da Cova da Beira. Aferiram-se vários conteúdos, nomeadamente a estrutura familiar e as condições de vida das famílias que 
intentam num projeto de construção de uma parentalidade, concluindo-se que são famílias predominantemente nucleares com maioritariamente 1 filho. A amostra não fica longe da realidade portuguesa, onde a média de filhos por casal ronda os 1,03 (INE, 2014). Os valores espelham o já advogado por Vanessa Cunha (2014), segundo a qual cada vez mais os casais ficam pelos filhos únicos e poucos intentam numa segunda gravidez, ou porque não percecionam os apoios (formais e informais) que necessitam ou pela precariedade laboral em que se encontram e que muitas vezes não traduz as habilitações das quais são detentores. A região da Cova da Beira também é parca em incentivos para a fixação das famílias e em particular para o aumento da natalidade. Os baixos rendimentos que caracterizam a amostra, aliados aos impostos e aos custos associados a viver numa região do interior do país. Talvez por isso, a razão mais mencionada pelos pais e mães para não terem filho(s) tenha sido a das questões financeiras. No entanto, uma percentagem da amostra mostrou desejo em intentar numa nova parentalidade, referindo "não quererem ficar só com um filho". Esta afirmação pode traduzir as motivações positivas mencionadas por Leal e Pereira (2005) e Guedes, Carvalho, Pires e Canavarro (2011) atribuindo este desejo à necessidade de alcançar um projeto de vida ou objetivo pessoal. Ou também por Hoghughi e Long (2004), como forma de assegurar a descendência da família e da transmissão das heranças familiares ou como apoio futuro na velhice e/ou para outro filho.

A forma como os progenitores transitam para a parentalidade pode ser determinante na motivação positiva ou negativa dos casais em terem filhos. Ficou demonstrado que a atitude evidenciada pelos pais perante esta transição era uma atitude moderadamente favorável, com as mães a apresentarem scores mais elevados, revelando mais facilidade neste processo adaptativo e de aprendizagem constante. O facto da trajetória masculina ter início mais tarde, com uma construção mais lenta da relação entre pai e filho, fortalecendo-se só após o nascimento e durante o desenvolvimento da criança (Piccinini, Silva, Gonçalves, Lopes \& Tudge, 2004), podem legitimar os resultados encontrados. Observe-se que os pais obtiveram scores representativos de uma atitude menos favorável tanto para o subgrupo da relação conjugal, como para o subgrupo da qualidade de vida (as mães apenas a apresentam para a relação conjugal). Martins (2009) refere que na relação conjugal existe uma redução geral na satisfação marital depois do nascimento, assim como aumento dos níveis de conflito para ambos os progenitores. Relativamente à qualidade de vida, fica patente que uma percentagem dos pais tem maior dificuldade em gerir a pressão associada ao nascimento do filho, de alterar o seu estilo de vida e bem-estar e de se organizar numa nova zona de conforto. Relativamente ao 
subgrupo "Competência e satisfação parental", as mães têm uma percentagem maior de scores para a atitude mais favorável, que pode perfeitamente estar relacionada com a construção da confiança sobre as suas competências e auto eficiência nos cuidados ao bebé, em comparação com os pais. O facto de, nas mães, a transição se iniciar antes ou durante a gravidez (Mercer, 2004) fará com que elas disponham de mais tempo para se prepararem, procurando informações e apoio nos mais diversos recursos humanos, materiais e instrumentais que tenham ao seu dispor.

Embora as mães revelem atitudes mais favoráveis, é nelas que a estrutura familiar exerce maior influência na transição para a parentalidade, como revelaram os testes estatísticos. A pesquisa bibliográfica refere que, independentemente da sua estrutura, a família é a base fundamental para a promoção de um desenvolvimento harmonioso dos seus membros e que atualmente os papéis dos cônjuges começam a equiparar-se, com os direitos e deveres a serem cada vez mais partilhados. Mas os resultados obtidos levam a considerar que é a mulher quem é mais dependente da forma como a família se organiza e interage, conferindo-lhe um papel de maior comprometimento, seja pelo peso do trabalho que recai sobre elas, seja pelo facto de assumirem com mais frequência a maternidade sozinhas, tornando-se mães solteiras com necessidade de um apoio de retaguarda mais próximo e ativo. É, no entanto, pertinente referir que o facto de ter havido pouca variação no que concerne à tipologia de famílias incluídas na amostra pode explicar este resultado (apenas duas famílias monoparentais cujo progenitor presente é a mãe, logoé ela que vivencia o facto de estar sozinha a cuidar de uma criança e as eventuais dificuldades que resultem desta situação).

Tendo presente que muitas vezes a estrutura familiar depende diretamente do rendimento disponível pelas famílias e da classe social a que pertencem, analisou-se se, de alguma maneira, a classe social e o rendimento líquido auferido pelas famílias influenciavam o desejo dos pais de terem mais filhos, concluindo-se que nenhuma das duas variáveis parece exercer influência nessa decisão. Recordando o que foi exposto por Cruz (2011), existe uma relação positiva entre a decisão de ter um filho e a participação da mulher no mercado de trabalho, devido à importância dos rendimentos auferidos, mas Rosa e Mendes (2014) também declaram haver uma tendência nas mulheres desempregadas ou nas que se encontram na situação de trabalhador familiar não remunerado em desejarem ter mais filhos.

Tornou-se assim pertinente perceber se as redes sociais de apoio influenciavam de algum modo a decisão dos pais em terem filhos e a própria transição para a parentalidade. As famílias estudadas referiram os avós das crianças como as principais fontes de apoio a quem recorrem, embora percecionem as redes formais, 
nomeadamente profissionais de saúde e instituições como os jardins-de-infância, como aquelas que fornecem um grau de ajuda mais elevado. Relativamente ao tipo de apoio, aquele que de facto recebem é o que desejavam receber, mencionando o apoio emocional providenciado por parte dos amigos e o apoio informativo vindo dos profissionais. Canavarro e Pedrosa (2005) referem que o apoio emocional assim como o instrumental fornecido pelos avós é fundamental para o bem-estar e o equilíbrio psicológico dos progenitores, principalmente nos primeiros dias após o parto. Embora no caso das mães solteiras e segundo Dunst, Trivette e Cross (in Brandão \& Craveirinha, 2011), a possibilidade de uma rede social menos estável conduza a que o papel de profissionais possa ser fundamental, especialmente quando estas mães e seus filhos estão longe de outros familiares, se encontram isoladas, ou se deparam com atitudes negativas por parte da família alargada ou dos elementos da comunidade onde vivem.

Quando se pretendeu verificar através de testes estatísticos se as fontes e tipos de apoio determinavam o desejo de ter filhos, os resultados mostraram que tal não acontece, em oposição à influência do apoio recebido e que de facto já condiciona o desejo de ter filhos a posteriori. Poderá, numa primeira leitura, parecer existir um contrassenso, mas o que se pode concluir é que não interessa de onde vem o apoio, desde que este exista e a ele os pais possam recorrer quando necessitarem. Esta afirmação foi corroborada pelos testes de hipóteses efetuados no decurso da investigação, donde emergiu que a existência de redes sociais não determina nem condiciona a decisão das famílias da Cova da Beira em terem filhos, mas o apoio que recebem das mesmas, nomeadamente da rede informal, é relevante para que o processo de transição para a parentalidade decorra mais facilmente. Constando-se ainda que este facto é transversal quer à classe social quer aos rendimentos da família. É a rede informal que assume o papel de suporte e apoio preferencial das famílias e aquela que permite às mesmas uma adaptação mais positiva e bem-sucedida nesta nova etapa da vida. Mais uma vez os resultados obtidos vão ao encontro dos estudos efetuados por Dessen e Braz (2000), Jussani, Serafim e Silva (2007) e Murta, Rodrigues, Rosa e Paulo (2012), onde se mencionam os familiares diretos como as fontes cujo apoio é um fator de proteção e fundamental para o bem-estar emocional das mães e dos pais.

$\mathrm{O}$ facto de as famílias poderem recorrer à sua rede próxima para o apoio, o que ficou patente nos resultados obtidos, é uma mais-valia nos cuidados às crianças. A transmissão de conhecimentos e experiência é determinante para capacitar os pais para o exercício de uma parentalidade consciente e responsável, principalmente num meio onde os apoios formais não são de todo percecionados e aproveitados. Se o processo de transição for facilitado, poderá eventualmente aumentar o desejo nos pais de terem mais filhos. 
Fazer com que a informação e o apoio cheguem de forma ordenada e abrangente é uma aposta que pode fazer a diferença e permitir que os pais apresentem uma atitude mais favorável no percurso da transição para a parentalidade, principalmente para aqueles que decidem encetar um projeto de vida longe da família e amigos e que por esse motivo deixam de poder contar com o apoio e sapiência da geração antecessora.

Assim, e na sequência dos resultados obtidos no quadro da presente investigação, julgamos pertinente propor-se um maior investimento público, em estreita articulação com as organizações da sociedade civil, na promoção de redes de apoio formais, para jovens e adultos, em temáticas específicas sobre a parentalidade, bem como a necessária articulação dos diferentes grupos de apoio já existentes na região da Cova da Beira (Linha de Apoio no Aleitamento Materno, visita domiciliária de obstetrícia, aulas de preparação para o parto e grupo de mães de trocas de experiencias na amamentação). O objetivo principal seria o da promoção de atividades na área da educação, saúde e do aconselhamento aos pais através da gestão da informação a transmitir e das formações necessárias, adaptadas às diferentes etapas da transição para a parentalidade e às reais necessidades de cada família, proporcionando espaços de aconselhamento e de consulta, onde a qualquer momento os pais pudessem recorrer.

Numa região demograficamente marcada pelo envelhecimento e pela baixa natalidade urge apostar em sessões de consciencialização junto dos autarcas locais, sobre a importância de investir não só em medidas de incentivo à natalidade mas também na promoção de redes de apoio formais em temáticas específicas sobre a parentalidade. Este é o desafio que se lança e se deixa à consideração, num cenário em que são grandes os riscos de a região ver agravar a saída dos jovens casais. Atualmente ainda existem alguns jovens adultos que podem contribuir para o crescimento e desenvolvimento do interior, mas parece ser essencial que o interior contribua ativamente para a promoção do bem-estar desses mesmos jovens e crie condições para que os mesmos permaneçam na região. Os resultados obtidos conduzem-nos a pensar que estas medidas por si só, poderão não ser suficientes para incrementar os nascimentos nesta região, até porque a baixa natalidade está diretamente relacionada com medidas mais gerais e legislativas e que resultam das políticas nacionais efetivas. Perceber que tipo de medidas adicionais poderiam ser tomadas pelas autarquias e entidades patronais no sentido de estimularem um aumento da natalidade, será o possível mote para um outro estudo que venha a complementar este. 


\section{Notas}

Por decisão pessoal, os autores do texto escrevem segundo o novo acordo ortográfico.

\section{Referências}

Almeida, A. M. (2008). O caso da Guarda. In: A. A. Monteiro \& F. B. Ribeiro (Orgs), Redes Sociais: Experiências, Políticas e Perspectivas (pp. 21-31). Ribeirão: Húmus.

Bayle, F. (2005). A Parentalidade. In I. Leal, Psicologia da Gravidez e Parentalidade (pp. 317-346). Lisboa: Fim de Século.

Branco, P., \& Pedroso, J. (2008). Mudam-se os tempos, muda-se a família. As mutações do acesso ao direito e à justiça de família e das crianças em Portugal. Revista Crítica de Ciências Sociais, 82, 53-83.

Brandão, T., \& Craveirinha, F. (2011). Redes de apoio social em famílias multiculturais, acompanhadas no âmbito da intervenção precoce: um estudo exploratório. Análise Psicológica, 29(1), 27-45.

Canavarro, C., \& Pedrosa, A. (2005). Transição para a parentalidade: Compreensão Segundo Diferentes Perspectivas Teóricas. In I. Leal, Psicologia da Gravidez e Parentalidade (pp. 225-255). Lisboa: Fim de Século.

Coutinho, T. (2004). Apoio à família e formação parental. Análise Psicológica, 22(1), 55-64.

Cowan, P., \& Hetherington, E. (1991). Family transitions (Vol. 2). London: Lawrence Erlbaum Associates.

CLAS, (2012). Diagnóstico Social, Covilhã. Covilhã: Camara Municipal da Covilhã.

Clavel, G. (2004). A Sociedade da Exclusão - Compreendê-la para dela sair, Porto: Porto Editora.

Cruz, F. (2011) Variabilidade ou Convergência? Análise Regional da Fecundidade em Portugal (1980-2009). Lisboa: Universidade Nova de Lisboa.

Cunha, V. (2014). Quatro Décadas de Declínio da Fecundidade em Portugal. In: INEInquérito à Fecundidade 2013 (pp. 19-28). Lisboa: INE.

Dessen, M., \& Braz, M. (2000). Rede social de apoio durante transições familiares decorrentes do nascimento de filhos. Psicologia: Teoria e Pesquisa, 16(3), 221-231.

Guedes, M., Carvalho, P., Pires, R. \& Canavarro, M. (2011). Uma abordagem qualitativa às motivações positivas e negativas para a parentalidade. Análise Psicológica, 29(4), 535-561.

Gomes, C. S. \& Moreira, M. J., (2014). Dinâmicas demográficas do envelhecimento: análise retrospectiva e questões actuais. In Dinâmicas demográficas e envelhecimento da população portuguesa (1950-2011): evolução e perspectivas (pp. 111-167). Lisboa: Fundação Francisco Manuel dos Santos.

Gouveia, R. (2014). Personal networks in Portuguese society: a configurational and lifecourse approach. Tese de Doutoramento, Universidade de Lisboa - Instituto de Ciências Sociais, Lisboa, Portugal.

Hoghughi, M., \& Long, N. (2004). Handbook of Parenting: Theory and Research for Practice. London: Sage Publications. 
INE. (2014). Inquérito à Fecundidade 2013. Lisboa: INE.

Jussani, N. C., Serafim, D., \& Silva, S. (2007). Rede social durante a expansão da família. Revista Brasileira de Enfermagem, 60(2), 184-189.

Leal, I. (2005). Psicologia da Gravidez e Parentalidade. Lisboa: Fim de século, 2005.

Leal, I., \& Pereira, A. (2005). Infertilidade: Algumas Considerações Sobre Causas e Consequências. In I. Leal, Psicologia da Gravidez e Parentalidade (pp. 151-173). Lisboa: Fim de Século.

Maximino, V., Liberman, F., Frutuoso, M., \& Mendes, R. (2017). Profissionais como produtores de redes: tramas e conexões no cuidado em saúde. Saúde e Sociedade, $26(2), 435-447$.

Martins, C. (2009). Transição para a parentalidade: Uma revisão sistemática da literatura. In II Simpósio Internacional de Enfermagem de Família (pp. 115-128). Porto: Linha de Investigação de Enfermagem de Família.

Mercer, R. (2004). Becoming a Mother Versus Maternal Role Attainment. Journal of nursing scholarship, 36(3), 226-232.

MTSS. (2009). A dependência: o apoio informal, a rede de serviços e equipamentos e os cuidados continuados integrados. Lisboa: Gabinete de Estratégia e Planeamento (GEP), Ministério do Trabalho e da Solidariedade Social (MTSS).

Moreira, M. J., \& Gomes, C. S. (2014). Evolução da população portuguesa. In Dinâmicas demográficas e envelhecimento da população portuguesa (1950-2011): evolução e perspectivas (pp. 29-108). Lisboa: Fundação Francisco Manuel dos Santos.

Murta, S., Rodrigues, A., Rosa, I, \& Paulo, S. (2012). Avaliação de um programa psicoeducativo de transição para a parentalidade. Paideia, 22(53), 403-412.

Nyström, K., \& Öhrling, K. (2004). Parenthood experiences during the child's first year: literature review. Journal of advanced nursing, 46(3), 319-330.

Piccinini, C., Silva, M., Gonçalves, T., Lopes, R., \& Tudge, J. (2004). O Envolvimento Paterno durante a Gestação. Psicologia: Reflexão e Crítica, 17(3), 303-314.

PORDATA. (2015, Novembro 16). Taxa Bruta de Natalidade. Disponível em: http://www.pordata.pt/.

PORDATA. (2017, Novembro 16). Nados-vivos de mães residentes em Portugal: total e fora do casamento. Disponível em: http://www.pordata.pt/.

Portugal, S. (1995). As mãos que embalam o berço. Um estudo sobre redes informais de apoio à maternidade. Revista Crítica de Ciências Sociais, 42, 155-178.

Portugal, S. (2005, abril). "Quem tem amigos, tem saúde": O papel das redes sociais no acesso aos cuidados de saúde. Simpósio "Família, Redes Sociais e Saúde", Berlim, Alemanha, 7 e 8.

Relvas, A., \& Lourenço, M. (2001). Uma Abordagem Familiar da Gravidez e da Maternidade: Perspectiva Sistémica. In M. C. Canavarro, Psicologia da Gravidez e Maternidade (pp. 105-132), Coimbra: Quarteto.

Ribeiro, C., Gomes, R., \& Moreira, M. (2014). A paternidade e a parentalidade como questões de saúde frente aos rearranjos de gênero. Ciência \& Saúde Coletiva, 20(11), 3589-3598. 
Rodrigues, A. (1991). Psicologia social. Petrópolis: Vozes.

Rosa, M. J., \& Mendes, M. F. (2014). Os Sentidos da Fecundidade em Portugal. In: INE Inquérito à Fecundidade 2013 (pp. 95-104). Lisboa: INE.

Sanches, A., \& Manso, M. (s.d.). O pilar da parentalidade é as pessoas terem trabalho, remunerado de forma condigna. Retirado de https://www.publico.pt/.

Wall, K., Aboim, S., Cunha, V., \& Vasconcelos, P. (2001). Families and Informal Support Networks in Portugal: The Reproduction of Inequality, Journal of European Social Policy, 11(3), 213-233.

Williams, F. (2010). Repensar as famílias. Lisboa: Principia.

Ana Rosa Pinto. Licenciada em Enfermagem e Mestre em Empreendedorismo e Serviço Social.

Alcides A. Monteiro. Doutor em Sociologia; Professor Auxiliar com Agregação na Universidade da Beira Interior, Faculdade de Ciências Sociais e Humanas, Departamento de Sociologia; Investigador do CIES-IUL.

Data de submissão: 22/04/2017 | Data de aceitação: 18/07/2018

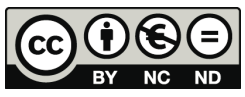

